\title{
Seven-year retrospective analysis of the myopic control effect of orthokeratology in children: a pilot study
}

This article was published in the following Dove Press journal:

Clinical Optometry

28 January 2011

Number of times this article has been viewed

\author{
Alan Kwok-Hei Mok ${ }^{1,2}$ \\ Cindy Sin-Ting Chung \\ 'Eye'ni, Hong Kong, People's Republic \\ of China; ${ }^{2}$ Department of Anatomy, \\ LiKaShing Faculty of Medicine, The \\ University of Hong Kong, Hong Kong, \\ People's Republic of China
}

Objectives: To investigate retrospectively the difference in myopia progression, over about 7 years, between two groups of Hong Kong Chinese myopic children who wore overnight orthokeratology lenses or single-vision spectacles.

Methods: A total of 238 records of children wearing overnight orthokeratology lenses or single-vision spectacles from Eye'ni optical shop (Hong Kong) between January 1999 and December 2009 were reviewed. Refractive and central corneal curvature data with 6-year or a longer follow-up period of 70 patients were retrieved: 34 children ( 15 boys and 19 girls, aged $9.2 \pm 1.8$ years) wore orthokeratology lenses and 36 (20 boys and 16 girls, aged $10.2 \pm 2.0$ years) wore spectacles. Myopic progression was determined as the change of myopia from the baseline to the final visit.

Results: No statistically significant differences $(P>0.05)$ in age, central flat corneal curvatures, baseline refractive error, or follow-up period were observed between the two groups. Average myopic progression of the overnight orthokeratology contact lens cohort $(-0.37 \pm 0.49 \mathrm{D})$ was significantly less $(P<0.001)$ than of the single-vision spectacle group $(-2.06 \pm 0.81 \mathrm{D})$ over about 7 years.

Conclusion: Our preliminary 7-year data support the claim that overnight orthokeratology contact lenses may be a feasible clinical method for myopic progression control. Prospective and randomized investigations are warranted to overcome the limitations of this retrospective study.

Keywords: myopia, contact lens, orthokeratology, myopia progression

\section{Introduction}

Orthokeratology contact lenses began to be fitted in the late 1960s. At this time, the technique suffered because only a small amount of myopia was corrected, the time for the correction to occur was long, and the technique was unpredictable. Changes in technology and design have made orthokeratology a predictable means of correcting low to moderate myopia safely, such that the technique is now used as an overnight modality in children. New materials with higher oxygen permeability and reverse geometry contact lens design allow myopic children to wear the contact lenses during sleep to temporarily flatten the central cornea (overnight orthokeratology). An orthokeratology lens flattens the central cornea while it steepens the mid-peripheral cornea. This rearrangement of the shape of the cornea induces peripheral myopic defocus. Several investigations ${ }^{1-3}$ propose that peripheral myopic defocus may play a vital role in myopic progression; thus overnight orthokeratology is hypothesized to control myopic progression. ${ }^{4-8}$ Two longitudinal clinical trials ${ }^{4,5}$ have proposed that overnight orthokeratology may slow
Correspondence: Alan Kwok-Hei Mok Eye'ni G/F 63 Lee Garden Road, Causeway Bay, Hong Kong, People's Republic of China

Fax +85228822959

Email mokkwokhei@gmail.com
Clinical Optometry 20I I:3 I-4

(C) 20II Mok and Chung, publisher and licensee Dove Medical Press Ltd.This is an Open Access article which permits unrestricted noncommercial use, provided the original work is properly cited.
Dovepress

DOI: 10.2147/OPTO.S16599 
myopia progression in children. The aim of this pilot report was to investigate the difference in myopia progression, over 7 years, between two groups of myopic children who wore either orthokeratology lenses or single-vision spectacles. A retrospective review may provide preliminary data to justify conducting a prospective and randomized long-term study on the effect of orthokeratology on myopia progression, since no report of the effect of orthokeratology contact lens on myopia progression over this length of time exists in the peer-reviewed literature.

\section{Methods}

A total of 238 records of children undergoing overnight orthokeratology lenses or single-vision spectacles from Eye'ni optical shop (Hong Kong) between January 1999 and December 2009 were reviewed. Myopic subjects with less than -1.00 cylindrical power, who were aged between 7 and 13 years and wore single-vision spectacles constantly or orthokeratology lenses and had 6-year or longer follow-up records were chosen. The 6-year period was arbitrary but was the longest follow-up period for which we could retrieve the appropriate number of cases for a meaningful statistical and clinical analysis. A total of 70 patients who fulfilled the inclusion criteria were retrieved: 34 children (15 boys and 19 girls, aged $9.2 \pm 1.8$ years) who wore orthokeratology lenses and 36 (20 boys and 16 girls, aged $10.2 \pm 2.0$ years) who wore spectacles. The spectacle lens wearing group had their prescription fully corrected. Reverse geometry lenses (Dreimlens, E and E optics, Hong Kong) in spherical, fourcurve design, with back optical zone diameter of $6 \mathrm{~mm}$ made of Boston XO (DK 100 ISO/Fatt units) material, were applied. The standard fitting guidelines were clear and were applied by all the optometrists. Although the manufacturer generally needs patient information including refraction, keratometry readings, and e-value for lens ordering, all contact lenses were ordered based on the in-office trial lens fitting. The spherical component of the manifest refraction and the flat keratometry readings were used to determine the initial trial lenses, which were placed on the eye and evaluated for a proper fit. Where appropriate, lens parameters were modified to achieve the optimal fitting. All children reported compliance with the wearing of the contact lenses for at least 7 hours every night. They had at least two aftercare visits per year and replaced the new lenses within 1.5 years. Boston cleaner, Boston conditioning solution (Bausch and Lomb), and Unizyme enzymatic cleaners (CIBA Vision) were used for contact lens care. Clinical data, including manifest refractive error and central corneal curvature (the average value of three readings, NIDEK auto-keratometer, RKT-7700) were retrieved for comparison analysis. Our primary outcome is the myopic progression change from the baseline refraction (average of the initial two visits) and the final refraction (average of the last two visits). Determination of the final refractive error of the orthokeratology lens wearing subjects was conducted by the washout period method. ${ }^{9}$ Subjects were refracted after not wearing the lenses for a period of time until the flat corneal curvature reverted to its pre-orthokeratology value. Only the sphere component was considered in all cases.

Differences in clinical readings between overnight orthokeratology contact lens and single-vision spectacle groups were assessed with the unpaired student $t$-test. A $P$-value $<0.05$ was considered statistically significant.

\section{Results}

No statistically significant differences $(P>0.05)$ in age, central flat corneal curvatures, baseline refractive error, or follow-up period were observed between the two groups (Table 1). For orthokeratology groups, the average washout period was $25.5 \pm 1.0$ (range 22-29) days, and no statistically significant difference in central flat corneal curvature values were observed between pre-orthokeratology and after the washout period (paired $t$-test, $P=0.10$ ). Final refractive error of the overnight orthokeratology contact lens cohort was significantly less $(P<0.001)$ than the single-vision spectacle group (Table 1). The average myopic progression of the overnight orthokeratology contact lens cohort $(-0.37 \pm 0.49 \mathrm{D})$ was statistically significantly less $(P<0.001)$ than of the single-vision spectacle group $(-2.06 \pm 0.81 \mathrm{D})$. Table 2 shows the pattern of myopic changes over the follow-up period in the two groups.

\section{Discussion}

About $-2.00 \mathrm{D}$ myopic progression was found in the single-vision spectacle group over about 7 years. The pattern of myopic changes appeared constant during our timeframe. Since there was a limited number of subjects, further investigation is highly recommended. Results from our retrospective pilot review agree with previous investigations $\mathrm{s}^{4,5}$ - that overnight orthokeratology contact lenses may clinically and statistically slow myopia progression in children. We found more reduction in myopia progression, approximately $80 \%$, than has been reported in previous studies $(45 \%-55 \%))^{4,5}$ The reason for the difference is unclear and might be explained by the longer treatment 
Table I The clinical data between the two groups

\begin{tabular}{|c|c|c|c|}
\hline & $\begin{array}{l}\text { Orthokeratology }(n=36) \\
\text { mean } \pm \text { SD (range) }\end{array}$ & $\begin{array}{l}\text { Spectacle }(n=34) \\
\text { mean } \pm \text { SD (range) }\end{array}$ & $P$-value \\
\hline Age (years) & $\begin{array}{l}9.2 \pm 1.5 \\
(7-12)\end{array}$ & $\begin{array}{l}10.2 \pm 1.3 \\
(7-13)\end{array}$ & 0.12 \\
\hline $\begin{array}{l}\text { Baseline flat central corneal } \\
\text { curvature }(\mathrm{mm})\end{array}$ & $\begin{array}{l}7.65 \pm 0.20 \\
(7.50-8.10)\end{array}$ & $\begin{array}{l}7.69 \pm 0.18 \\
(7.55-8.10)\end{array}$ & 0.15 \\
\hline $\begin{array}{l}\text { Baseline flat central corneal } \\
\text { curvature }(\mathrm{mm})\end{array}$ & $\begin{array}{l}7.67 \pm 0.19 \\
(7.50-8.10)\end{array}$ & $\begin{array}{l}7.72 \pm 0.22 \\
(7.55-8.10)\end{array}$ & 0.20 \\
\hline Initial refractive error (D) & $\begin{array}{l}-2.88 \pm 0.49 \\
(-1.25 \text { to }-3.75)\end{array}$ & $\begin{array}{l}-2.60 \pm 0.61 \\
(-1.00 \text { to }-3.50)\end{array}$ & 0.22 \\
\hline Follow-up period (years) & $\begin{array}{l}7.4 \pm 0.9 \\
(6-9)\end{array}$ & $\begin{array}{l}7.0 \pm 0.7 \\
(6-8)\end{array}$ & 0.58 \\
\hline Final refractive error (D) & $\begin{array}{l}-3.25 \pm 0.49 \\
(-1.50 \text { to }-4.00)\end{array}$ & $\begin{array}{l}-4.69 \pm 0.81 \\
(-2.50 \text { to }-450)\end{array}$ & $<0.001$ \\
\hline
\end{tabular}

Abbreviation: SD, standard deviation.

period. Overnight orthokeratology contact lens would induce more spherical aberration with higher the myopia correction, theoretically this may enhance the myopia control effect. ${ }^{7,8}$ In contrast, increasing myopic spectacle lens power induces more peripheral hyperopic defocus, which is thought to further increase myopia. ${ }^{10}$ Further study is warranted to validate this hypothesis.

There are several limitations of the current pilot review. We well understood that a direct measure of refractive error in orthokeratology lens wearers was unlikely the most appropriate measure of myopia progression. ${ }^{9}$ Since our clinical records were not designed specifically for myopia research, only refractive progression could be used as a measure of myopia progression. In addition, refractions were not made under cycloplegia, and were conducted by different optometrists. Overnight orthokeratology contact lenses were fitted by a variety of optometrists. Ocular components, notably axial vitreous length, were not measured. Since we analyzed the data only of subjects having a history of follow-up of at least 6 years, these subjects adapt well to

Table 2 Patterns of myopic changes over the follow-up period in two groups

\begin{tabular}{lll}
\hline & \multicolumn{1}{l}{ Spectacle } & Orthokeratology \\
\hline Baseline & $-2.60 \pm 0.61 \mathrm{D}$ & $-2.88 \pm 0.49 \mathrm{D}$ \\
First year & $-2.91 \pm 0.58 \mathrm{D}$ & $-3.00 \pm 0.50 \mathrm{D}$ \\
Second year & $-3.22 \pm 0.66 \mathrm{D}$ & $-3.03 \pm 0.52 \mathrm{D}$ \\
Third year & $-3.50 \pm 0.62 \mathrm{D}$ & $-3.08 \pm 0.45 \mathrm{D}$ \\
Fourth year & $-3.88 \pm 0.59 \mathrm{D}$ & $-3.15 \pm 0.50 \mathrm{D}$ \\
Fifth year & $-4.09 \pm 0.60 \mathrm{D}$ & $-3.13 \pm 0.48 \mathrm{D}$ \\
Sixth year & $-4.35 \pm 0.68 \mathrm{D}$ & $-3.18 \pm 0.5 \mathrm{D}$ \\
Final data & $-4.69 \pm 0.8 \mathrm{D}$ & $-3.25 \pm 0.49 \mathrm{D}$ \\
\hline
\end{tabular}

the overnight orthokeratology contact lenses. If lens adaptation is directly related to myopic control performance, the findings would likely to be biased to the positive effects. However, the reason for the loss to follow-up at our center was unlikely to be due to the unsatisfactory control of myopia progression since their myopic changes were all within $-0.50 \mathrm{D}$ at the last visit compared with the baseline refraction.

Although several limitations in this retrospective pilot review have been identified, it offers several significant features: well matched subjects (gender, age, and baseline refractive error) were followed up over a longer period than has ever been reported before (about 7 years). The maximum follow-up prior to this has been 2 years. ${ }^{4,5}$ Our preliminary data support the claim that overnight orthokeratology contact lenses may be a feasible clinical method for myopic progression control. Prospective and randomized investigations are warranted to overcome the limitations of this retrospective study. ${ }^{11}$ In addition, although no serious complications such as microbial keratitis or corneal abrasion were reported, the safety of overnight orthokeratology should be further addressed. A formal prospective report on the incidence of adverse events association with overnight orthokeratology contact lenses specifically used to treat myopia is necessary.

\section{Acknowledgments}

The authors would like to thank Mr Neddy Siu-Kan Fung for proposing this work.

\section{Disclosure}

The authors report no conflicts of interest in this work. 


\section{References}

1. Smith EL, Kee CS, Ramamirtham R, et al. Peripheral vision can influence eye growth and refractive development in infant monkeys. Invest Ophthalmol Vis Sci. 2005;46:3965-3972.

2. Mutti DO, Hayes JR, Mitchell GL, et al. Refractive error, axial length, and relative peripheral refractive error before and after the onset of myopia. Invest Ophthalmol Vis Sci. 2007;48:2501-2509.

3. Schmid GF. Variability of retinal steepness at the posterior pole in children 7-15 years of age. Curr Eye Res. 2003;27:61-68.

4. Cho P, Cheung SW, Edwards M. The longitudinal orthokeratology research in children (LORIC) in Hong Kong: a pilot study on refractive changes and myopic control. Curr Eye Res. 2005;30:71-80.

5. Walline JJ, Jones LA, Sinnott LT. Corneal reshaping and myopia progression. Br J Ophthalmol. 2009;93:1181-1185.
6. Reim TR, Lund M, Wu R. Orthokeratology and adolescent myopia control. Contact Lens Spectrum. 2003;18:40-42.

7. Joslin $\mathrm{CE}, \mathrm{Wu} \mathrm{SM}, \mathrm{McMahon} \mathrm{TT}$, et al. Higher-order wavefront aberrations in corneal refractive therapy. Optom Vis Sci. 2003;80: $805-811$.

8. Asbell PA. Corneal refractive therapy and the corneal surface. Eye Contact Lens. 2004;30:236-237.

9. Walline JJ. Study design issues in a corneal reshaping contact lens myopia progression study. Eye Contact Lens. 2004;30:227-229.

10. Lin Z, Martinez A, Chen X, et al. Peripheral defocus with single-vision spectacle lenses in myopic children. Optom Vis Sci. 2010;87:4-9.

11. Santodomingo-Rubido J, Villa-Collar C, Gilmartin B. Myopic control with orthokeratology contact lenses in Spain (MCOS): study design and general baseline characteristics. J Optom. 2009;2:215-222.
Clinical Optometry

\section{Publish your work in this journal}

Clinical Optometry is an international, peer-reviewed, open access journal publishing original research, basic science, clinical and epidemiological studies, reviews and evaluations on clinical optometry. All aspects of patient care are addressed within the journal as well as the practice of optometry including economic and business analyses. Basic and clinical

\section{Dovepress}

research papers are published that cover all aspects of optics, refraction and its application to the theory and practice of optometry. The manuscript management system is completely online and includes a very quick and fair peer-review system, which is all easy to use. Visit http://www.dovepress. com/testimonials.php to read real quotes from published authors. 